\title{
Loss Aversion: Will It Be Greater than the Gain?
}

\section{Hongren Zhao*}

School of Finance, City University of Macau, Macao 999078, China. E-mail: Fredericz@foxmail.com

\begin{abstract}
Loss aversion is one of the most widely accepted ideas in social science, that is, the loss is greater than the gain. This paper is divided into four parts. First of all, the construction of loss aversion is introduced and discussed. The second part is about the evidence that supports loss aversion. As a result, the current evidence does not support losses, which are generally more influential than gains. The third part is to solve the following questions: despite the evidence to the contrary, why aversion is still generally accepted as a general principle among social scientists, including consumer psychologists. The aim of the analysis is to link beliefs about loss aversion to more general concepts, such as acceptance and adherence to scientific beliefs. In the last part, how to understand the relative impact of loss and income from the context, and how to broaden the new field of investigation in the field of consumer psychology are discussed.
\end{abstract}

Keywords: Loss Aversion; Science; Gain

\section{Introduction}

One of us surveyed people at the Consumer Decision-Making Conference at the 2016 Judgment and Decision Making Association Meeting in Boston. The question is as followings.

Which of the following do you believe?
A. Losses outweigh gains
B. Gains outweigh losses
C. Losses and earnings have a similar psychological impact

With the exception of three participants, all the participants say that they think the loss was greater than the gain. No one thinks that the gains outweigh the losses. And only three participants think that loss and income has roughly the same psychological impact. In the context of this view, participants were informed at a meeting that the theme discussed was that the concept of challenging losses was usually more prominent than gains. Similarly, new support is gotten when talking to colleagues from many universities.

Here, the rise of aversion are reviewed and discussed. The main conclusion is that the weight of evidence does not support the general trend that losses have a greater psychological impact than gains, that is, loss aversion. On the contrary, our comments show that it is necessary to look at from a more contextual point of view, sometimes the loss is greater than the gain, sometimes the loss and the gain have similar psychological effects, and sometimes the gain is greater than the loss. That is to say, the choice proposed at the beginning of this paper is wrong because it deprives the audience of the possibility of using a contextual perspective ${ }^{[1]}$. Instead, the question should provide a fourth option: all of the above are right, depending on the context.

This is an open-access article distributed under the terms of the Creative Commons Attribution Non-Commercial License (http://creativecommons.org/licenses/by-nc/4.0/), which permits unrestricted non-commercial use, distribution, and reproduction in any medium, provided the original work is properly cited. 


\section{What is loss aversion?}

In short, the loss aversion is psychologically more powerful than similar gains. In these ideas, some people think that the loss is about twice as much as the gain that makes us feel good. Importantly, losses and gains are different from changes in subjectively neutral reference points, for example, the status quo. For example, an individual who receives $\$ 5$ may think that $\$ 5$ is an income, while another person who expects $\$ 10$ but only receives $\$ 5$ may consider an expected loss of $\$ 5$ relative to his or her income $\$ 5$.

There are two worthy aspects of loss aversion. First, most articles about loss aversion assume that this is a basic dynamic principle, not a context. Second, for psychological principles, the loss aversion is not typical because it is not commensurate with the psychological process ${ }^{[2]}$. Both behaviors deserve further discussion in order to correctly understand the structure of loss aversion. This observation does not mean that researchers who accept loss aversion as a general principle are so narrow-minded that it is obvious that loss aversion is common. But as mentioned earlier, in general, there is no effort to demonstrate the characteristics of losses, nor is it clear that, for example, certain situations and psychological processes have similar psychological effects on losses and gains. Or the gain outweighs the loss. In fact, even when researchers who accept loss tendencies discuss "loss aversion limits", they tend to reinforce and anchor the basic concept that loss is fundamentally greater than gain ${ }^{[3]}$.

In other words, their boundary condition is not that they believe that loss equals gain, but that they are not aware of the loss. Therefore, this is not the boundary condition of wear and tear aversion itself. Similarly, in the comment entitled "when the loss is greater than the gain", Ariely, Huber and Witten Brock (2005) did not question the universality of loss. Fundamentally, it is greater than the gain, but it means it is possible to avoid losses. In short, most books on loss aversion seem to accept the assumption that losses are indeed greater than gains and deviations, rather than gains and deviations, which is an anomaly, violates norms and does not challenge fundamentals.

As further support for this view, the introduction of arbitrator research as evidence of loss aversion, for example, status quo bias, is not seen as evidence of loss aversion, nor as a challenge to loss aversion. On the contrast, these reducers are considered to be other factors that may affect a particular phenomenon, rather than an aversion to loss. Similarly, there is no doubt that people's aversion to loss does exist, but people recognize that in a given environment and other facts may move in the opposite direction.

Secondly, the loss aversion is descriptive rather than explanatory. In other words, loss aversion is explicitly introduced into averages to describe rather than explain behavior. In short, aversion to loss has always been regarded as a basic principle, that is, loss outweighs gain, and it is considered to be a feature of human behavior. Next, a rigorous review of the evidence of this idea will be conducted.

\section{Evidence of loss aversion}

If loss aversion is a general psychological principle, what will expect to follow? For us, it depends on how the aversion to loss disappears. Here, two possible forms of loss aversion are considered ${ }^{[4]}$.

The first form, which is called a powerful form of exposition, is that losses are already greater than gains, so it should be pointed out that losses have a greater impact on psychology. The psychological impact of the agreement will never be more than the gain, and the gain will outweigh the loss. This powerful version does not require that the loss must be greater than the gain in any case, because factors such as measurement errors and boundary conditions may blur or reduce the weighted loss, which is greater than the basis of the gain. However, to accept a strong loss aversion, one should not observe a trend of more profitability than similar losses.

As a general rule, another form of loss aversion is that loss is usually greater than gain. Unlike the forceful loss-averse version, this weak version allows people to show a greater sense of responsibility, and in some cases, people can seek income. However, if, on average, the data is expected to show that the impact of losses outweighs the impact of gains, a weaker version will be supported. If neither hypothesis is supported, the third possibility must be taken into account, that is, the similarity of the relative psychological effects of losses and gains may vary according 
to background factors, which is generally believed to be feasible to hate losses. and the relative intensity of psychological processes associated with losses and gains.

Similarly, in the absence of loss avoidance, another explanation for the effect of donation comes from We Averand Frederick (2012). These authors provide different reference price accounts. They believe that buyers and sellers face very different decisions when setting WTP and WTA amounts respectively, and they focus on different reference prices. For buyers, private use is the most prominent reference in the acquisition object. For the seller, the market value is the most prominent reference. Therefore, if the market price often exceeds the individual's valuation, the owner's demand for the product will exceed the price that potential buyers are willing to pay. For example, if both of the owner and the owner set the value of an object at $\$ 3$, but the market price is $\$ 7$, the owner will ask for $\$ 7$ to partially buy the item, while the owner will only have to pay $\$ 3$ for the item. Like inertia, the account is insensitive to losses and does not explain the effect of donations.

In the possible alternative explanation of loss aversion to the impact of donation discussed so far, there is no difference between the value of options and the value of non-donation options. However, the study also shows that those who give up "text termination in an election" are more likely to be positive about the right to choose than those who face the right to choose (Nayakan Kupam and Mishra, 2005; Johnson, Hauble and Keenan, 2007). This process may cause the valuation of options to be higher than that of unactivated options, so it can be interpreted as a process that leads to losses and large gains in the context of donation effects. However, these two warnings are orderly. First, because losses and gains are confused with inaction and action in the donor paradigm, rather than tend to reappear as an option for possible loss of promotion, this process may also re-emerge with a tendency to do nothing. Second, even if people accept the idea that there is a tendency to lose a choice in the effect of donation, it does not mean accepting aversion to loss. In particular, to accept the general principle of loss avoidance, at least evidence is needed to show that losses are greater than gains in different circumstances, including when losses and gains are confused with inaction and action ${ }^{[5]}$.

In fact, it is important to note that when applying the retention model, a design is needed so that the individual (a) assigned to the WTP retention condition interprets the transaction as a payment to avoid loss, and that (b) takes into account the fairness of the transaction. Gal and Rucker (2017) operates on cage c in a variety of ways, including WTP repair phones which are serviced under WTP-Access conditions, and is willing to take the time to drive to get unused new status laptops and is willing to spend time buying new laptops and to pay for retention services ${ }^{[6]}$.

As far as services are concerned, there is actually no ownership, but individuals can still interpret service losses as losses. For example, if someone's Internet service expires at the end of the month, the loss can be interpreted as a loss even if the person does not own the service, and the WTP-Retain usually does not exceed the WTP-Access. In fact, in most cases, there is little difference between the reserved WTP and the reserved WTP, and for general merchandise, the reserved WTP usually exceeds the reserved WTP. For example, participants reported that they were willing to pay more per month for fiber-optic Internet services $(\$ 50.43)$ than to pay more to retain the fiber-optic Internet services they had received $^{[7]}$.

Two different hypothetical scenarios of 182 participants to run the example are used. In one case, some people are given a pen or stick and have to choose whether or not to switch to another product. In the second competition, participants were given $\$ 5$ or a cup emblazoned with their favorite sports team logo, and then had to choose one to replace it. In both cases, the stock selected for the product is essentially the same, whether it is a granted option or an ungranted option. For example, when individuals have to choose a cup and $\$ 5$, they will choose a cup $26 \%$ of the time, whether it is a gift choice or a non-gift choice. In other words, participants chose option A (\$0 received) 26\% of the time when the cup was given, and option B (replace the cup with \$5) $26 \%$ of the time without a gift.

It is worth noting that when the same stimulus and donation paradigm is used for the overall operation of discrete changes. The typical result pattern will be replicated. For example, when participants choose $41 \%$ of the time, they get an option, but when it is not a given option, only $18 \%$ of the time. In subsequent studies, the discrete retention paradigm 
is run and the discrete final owl paradigm study at the same time and copy the result pattern. Therefore, unlike the prediction of loss aversion, which should have this link between the two models, simple program changes translate into simple program changes that lose and benefit from inaction, thus translating the preference of choice into "lemmy" ${ }^{[8]}$.

\section{Loss aversion sociology}

It is believed that, despite evidence to the contrary, the persistence and widespread acceptance of loss aversion is an interesting sociological phenomenon. In fact, from the current prejudice against the concept of competition, loss aversion is a hint of aversion. Here, why the acceptance of loss aversion has always been the belief of researchers is considered and it is associated with a broader view of the persistence of beliefs among scientists. In particular, with the idea that aversion to loss has become a scientific consensus, which itself resists change. In addition, the idea that aversion to loss has a unique appeal and that it may re-emerge as an overgeneralization trend is discussed.

Attempts to modify or adjust the expression of loss aversion, or to add advertising parameters are made in response to the fact that the loss is greater than the face value of the gain. For example, McGraw et al. (2010) believe that because people tend to assess losses and gains through different subjective assessments, the rating of the impact of losses and gains does not show aversion to losses. This is not to say that what these scholars do is inherently wrong or futile. They reveal a more profitable culture of how to assess the value of expected traded and untraded goods and gambling consumption. Nevertheless, these methods also reveal, as Kuhn describes, that scientists tend to pursue accepted paradigms rather than question their fundamentals in the face of contradictions.

Another possible reason for the intuitive appeal of loss aversion is that most people may have something to do with a rather painful loss and seem to be more painful than getting something. For example, one of us recently spent $\$ 2000$ to save a domestic dog from a life-threatening intestinal obstruction. The dog was rescued from the rescue station and the owner will not pay $\$ 2000$ for this dog. But now, he is the darling of his family. While examples of this lovely loss of feeling may help intuitively avoid loss, they do not actually represent aversion to loss. This is because people are more attached to some of the things they own (or pets) and pay more attention to them than that they did before they were attached. Not through gain, just because they are on different sides of the neutral reference point.

In short, it can be said that the name "loss aversion" represents a great brand, and from the point of view of enhancing the intuitive appeal of ideas, everyone is essentially opposed to loss (just as everyone is attracted by benefits). Such a good brand may prompt researchers to identify the phenomenon as supportive aversion, and although they involve losses, they do not involve comparing the effects of losses with equivalent gains. As mentioned in the previous section, examples include sunk costs, disposal effects, etc.

\section{The future}

Accepting loss aversion as a general principle may have unfortunate consequences and would rather conduct research to hide important research in order to explore common paradigms of ions. To illustrate this point, it is found that the loss aversion is not a general principle, so a new direction is proposed. These "research priorities" are called to encourage future work in this field.

\subsection{Impact of loss and income}

Perhaps the most obvious new direction is to research the relative impact of losses and gains as background functions. To elaborate rather than assume aversion to loss, a situational approach that encourages researchers to ask is preferred when the loss is greater than the gain, and vice versa. The purpose of this problem is not only to classify the situation where the loss is greater than the income, but also to better understand the psychological processes related to the gain and loss. It is believed that more and more attention to psychological processes that have a complete impact on losses and gains, as well as situational regulators that affect the relative intensity of these processes, will help to better understand how losses and gains affect behavior.

This approach does not avoid the possibility that the loss is greater than the gain in some cases, but it includes the 
possibility of treating the research event as a major loss, but there is no other possibility. The psychological impact is smaller than similar gains, and may even be less important than similar gains. In fact, the steady growth of emerging research is consistent with this concept. In addition, as more work turns to examining situations where losses are equally or less affected, it needs to be done from a contextual point of view.

As a retry to adapt to the environment, consider the work of Walasek and Stewart (2015). The author regards decision sampling as a potential source to avoid loss. In short, the author believes that individuals can prove that loss aversion, loss neutrality and loss aversion may be the result of changes in the scope of their losses and gains. For example, when the range of losses is small, for example, losses up to $\$ 20$ and gains range, for example, gains up to $\$ 40$, any given loss is psychologically affected because it represents a larger loss. Although losses can be weighted, increased or reduced for various reasons, these authors put forward the view that transcending aversion to loss is a basic principle and introduces an alternative, process-oriented view adapted to the situation.

In addition, some results indicates the need to examine the relative impact of losses and gains. One possible explanation is that there are strong social norms to protect natural wealth that does not exist in more common commodities. This may make people pay more to preserve such goods rather than buy them. The other option is that the loss of protected goods is considered irrevocable and therefore its interpretation is different from that of ordinary goods that can be easily replaced relatively ${ }^{[9]}$.

\subsection{Understanding the impact of differences in losses and gains}

In the psychological impact of floating profits, context does not mean that profits and losses should be treated in a similar manner. In fact, a vital problem is that even if gains and losses have similar effects on perception or method or avoidance behavior, gains and losses will have different effects on psychological processes. In fact, some researchers have provided evidence that although losses cannot be avoided over the pursuit of gains, they can focus more on losses than gains (Yechiam and Hochman, 2013). Similarly, the researchers think that losses and gains have different effects on certain types of behavior, including behaviors that are highly related to consumer researchers, such as consumer complaints. Therefore, one potentially productive way to study future research is to study how to deal with losses and gains in different ways and their different effects on specific emotions and behaviors.

\subsection{Check gain utility}

Consumer psychologists can also test the utility or pleasure people get from acquiring goods (utility; this has nothing to do with Taylor's "consumption", 1985). Utility is a "transaction" obtained by consumers. People may have nothing to do with getting utility from the value of the product used or the value of the transaction used in it. The idea has not been studied yet, which is surprising because Lays's experience shows that people get a lot of fun from what they get, whether it's shopping or gifts for themselves. Many of us are familiar with people who like shopping, but it seems to have little to do with throwing away items they buy excitedly and rarely use $\mathrm{e}^{[10]}$.

The relative lack of attention to pleasure can be traced back to the pain that researchers lost by watching consumers' behavior, which was lost due to an aversion to lenses. In any case, a survey of the utility of earnings is vital to the study of why people buy and buy things, which is at the heart of consumer research. Researchers as part of the pleasure survey may study how background affects the sense of pleasure associated with acquiring things.

\section{Conclusion}

In short, going beyond aversion to loss as a general principle and accepting more background knowledge about the psychological effects of gains and losses can provide a fruitful new starting point for important research issues. This does not confirm or negate the value of early papers and paradigms devoted to loss-averse research. However, the argument is that overgeneralization of loss aversion may confuse the psychological processes associated with loss and gain, leading to the idea that loss and gain are also psychologically obvious. Greater than the loss, or in other cases, profit or loss can have a similar psychological impact. In fact, more attention to psychological processes related to 
losses and gains and their context may increase scientific investigation and complexity, resulting in greater accuracy in predicting human behaviour. So, ironically, if this potential is realized, the aversion to losses may outweigh the benefits.

\section{References}

1. Apostolova-Mihaylova M, Cooper W, Hoyt G, et al. Heterogeneous gener effects under loss aversion in the economics classroom: A field 3. experiment. Southern Economic Journal 2015; 81: 980-994.

2. Donald B, Goldhaber D, Lanjford H, et al. The effect of certification and preparation on teacher quality. The Future of Children 2007; 1(1): 5-68.

3. Bibby PA, Ferguson E. The ability to process emotional information predicts loss aversion. Personality and Individual Differences 2011; 51: 263-266.

4. Colombatto E. The elgar companion to the economics of property rights. Cheltenham, UK: Edward Elgar; 2004.

5. Ernst C, Thöni C. Bimodal bidding in experimental all-Pay auctions. Games 2013; 4: 608-623. doi: $10.3390 / \mathrm{g} 4040608$.

6. Falk A, Fehr E, Huffman D. The power and limits of tournament incentives. Work in Progress 2008.

7. Nevill AM, Holder RL. Home advantage in sport. Sports Medicine 1999; 28(4): 221-236. doi: 10.2165/00007256-199928040-00001.

8. Francisco JS, Thomas FG. The rich get richer: Students' discounting of hypothetical delayed rewards and real effortful extra credit. Psychonomic Bulletin \& Review 2004; 11(6): 1124-1128. doi: 10.3758/BF03196747.

9. Sunde U. Heterogeneity and performance in tournaments: A test for incentive effects using professional tennis data. Applied Economics 2009; 41(25-27): 3199-3208. doi: 10.1080/00036840802243789.

10. Wicker P, Prinz J, Weimar D, Deutscher C, Upmann T. No pain, no gain? effort and productivity in professional soccer. International Journal of Sport Finance 2013; 8(2): 124-139. doi: 10.1016/j.tourman.2012.06.008. 